\title{
PENGARUH CHARACTER STRENGTH DAN DUKUNGAN SOSIAL TERHADAP RESILIENSI PADA PENGGUNA NAPZA
}

\author{
Syaiful Bahri \\ Anggota HIMPSI Provinsi
}

\begin{abstract}
Abstrak
Resiliensi merupakan salah satu bahan dasar untuk membawa ke kehidupan yang sehat dan menyenangkan. Dalam berbagai kajian, resiliensi dianggap sebagai kekuatan dasar yang menjadi fondasi dari semua karakter positif dalam membangun kekuatan emosional dan psikologis seseorang. Penelitian ini dilakukan dengan tujuan untuk mengetahui ada pengaruh yang signifikan character strength dan dukungan sosial terhadap resiliensi pada pengguna NAPZA dan variabel mana yang lebih besar pengaruhnya terhadap resiliensi pengguna NAPZA. Penelitian ini dilakukan pada 179 orang pecandu NAPZA yang berusia 18 tahun ke atas, memiliki kemampuan baca tulis dan kemampuan menganalisa yang masih memadai, dan terdaftar dalam panti rehabilitasi narkoba di PSPP Khusnul Khotimah Tangerang Selatan. Pengambilan data dilakukan dengan menggunakan skala Resilience Quotient (RQ), skala Values In Actrion - Inventory Strength (VIA-IS), dan skala Social Provisions Scale. Penelitian ini menggunakan skala kepuasan pernikahan yang diadaptasi dari Analisis data dilakukan menggunakan teknik analisis statistik regresi berganda dengan bantuan software PASW 18.0 dan LISREL 8.80. Berdasarkan hasil analisis diperoleh $R$ square $=0,651$.
\end{abstract}

Kata kunci: character strength, dukungan sosial, resiliensi 


\section{PENDAHULUAN}

Angka kambuhan (relapse) para pecandu di Indonesia secara statistik bisa dibilang cukup tinggi. Menurut Dr. Iskandar Irwan Hukom, MA dari Yayasan Cinta Anak Bangsa (YCAB), pada tahun 2008, 9 dari 10 orang pecandu NAPZA akan kembali menjadi pecandu (relapse) setelah di rehabilitasi. Angka yang tak jauh beda dengan data yang dikemukakan oleh Profesor George Koob, MD seorang ahli neuro-farmakologi dari Amerika Serikat (California), bahwa rata-rata dunia, 8 dari 9 pecandu akan relaps (Suriakusumah dalam Komunika, 2012).

Pada tahun 2007, NADA (National Anti - Drug Agency) melakukan penelitian mengenai penyalahgunaan NAPZA di Malaysia yang juga menunjukkan bahwa pengguna NAPZA lebih didominasi oleh pengguna kambuhan (relapse). Para pecandu baru dan kambuhan berjumlah 6.679 dan 7.810. Pada tahun 2008 yaitu 5.939 (48\%) pengguna baru dan 6.413 (52\%) pengguna kambuhan. (Ibrahim \& Kumar, 2009). Di Amerika sekitar $40 \%$ dari semua pasien yang dirawat karena memiliki ketergantungan terhadap bahan kimia (chemical dependency) merupakan para kambuhan yang sebelumnya pernah mengalami penanganan ketergantungan tersebut. Sebanyak $47 \%$ dari pasien yang mendapatkan program treatmen tersebut kembali menggunakan zat kimia setelah tahun pertama pasca proses treatmen.

Berkaitan dengan penyalahgunaan NAPZA dan Rehabilitasi, Relapse merupakan tantangan berat dalam pengobatan semua gangguan perilaku (Witkiewitz \& Marlatt, 2004). Beberapa penulis menjelaskan relapse adalah sesuatu yang kompleks, dinamis dan tak terduga (Buhringer, 2000; Donovan, 1996; Marlatt, 1996, dalam Ibrahim dan Kumar, 2012). Pada dasarnya, ketika seseorang mencoba untuk merubah perilaku bermasalah, kemunduran awal atau yang disebut dengan lapse sangatlah mungkin. Satu kemungkinan hasilnya adalah kembali ke pola perilaku bermasalah awal atau disebut relapse. Kemungkinan lainnya ialah ketika seseorang kembali ke pola perilaku positif awal atau disebut dengan prolapse (Witkiewitz \& Marlatt, 2004).

Data di atas menunjukkan bahwa usaha-usaha yang dilakukan baik itu dengan rehabilitasi atau pengobatan tradisional belum berjalan secara efektif karena mayoritas dari pemakai adalah bukan pemakai pertama atau pemakai yang kambuh (relapse). Pada dasarnya, tempat rehabilitasi tidak menjamin pasiennya untuk pulih secara total apabila tidak memiliki niat sendiri bahwa dirinya akan berhasil pulih. Saat keluar dari rehabilitasi, resiko relapse dapat terjadi jika pasien kembali bergaul dengan teman 
sesama pengguna NAPZA.

Untuk mengatasi masalah dan mempertahan kesehatan pada situasi yang beresiko tersebut maka perlu adanya resiliensi, karena resiliensi dipercaya sebagai kekuatan atau kemampuan untuk beradaptasi secara positif, atau kembali kepada funngsinya setelah seseorang mengalami pengalaman yang sulit, bukan hanya pemulihan namun pertumbuhan dan penguatan dari keterpurukan (Ryan \& Caltabiano, 2009).

Masten (2001) menjelaskan bahwa dalam berbagai kajian, resiliensi dianggap sebagai kekuatan dasar yang menjadi fondasi dari semua karakter positif dalam membangun kekuatan emosional dan psikologis seseorang. Resiliensi diigunakan untuk menggambarkan sebuah kualitas khusus dalam diri individu (Chang 2008). Sementara dalam Mutimer, Reece dan Matthew (2007) istilah resiliensi digunakan untuk menggambarkan masukan yang positif yang didapatkan oleh anak ketika menghadapi kesengsaraan.

Seseorang tidak secara tiba-tiba menjadi sosok yang resilien, tetapi terdapat beberapa faktor yang saling berinteraktsi dalam diri individu sehingga menjadikan individu tersebut resilien.

Chang (2008) mengemukakan dalam penelitiannya bahwa terdapat faktor internal yang diidentifikasi sebagai faktor protektif dari resiliensi yaitu trait positif dalam diri yang disebut dengan character strength atau kekuatan karakter. Character strength merupakan karakter baik yang mengarahkan individu pada pencapaian keutamaan, atau trait positif yang terefleksi dalam pikiran, perasaan dan tingkah laku (Park, Peterson, \& Seligman, 2004).

Chang menjelaskan dalam penelitiannya (2008) bahwa level resiliensi murid mengenai Appreciation of Beauty and Excellence sama seperti Gratitude secara signifikan lebih tinggi daripada murid yang memiliki resiliensi rendah. Sementara level resiliensi murid mengenai Humility/ Modesty secara signifikan lebih rendah dibanding dengen mereka yang memiliki tingkat resiliensi rendah. Walaupun di dalam penelitian Chang dikatakan bahwa Love tidak memiliki hubungan yang signifikan dengan resiliensi, namun tingkat Love terhadap murid yang memiliki tingkat resiliensi yang tinggi secara relative lebih tinggi daripada mereka yang memiliki resiliensi yang rendah.

Selain Character strength, faktor lain yang berkaitan dengan resiliensi yaitu dukungan sosial. Fribourg, dkk (dalam Ryan \& Caltabiano, 2009) mengatakan bahwa dukungan keluarga dan dukungan sosial adalah faktor eksternal yang memengaruhi resiliensi dalam mengatasi kesulitan. Sementara hasil penelitian yang dilakukan oleh Hasyim (2009) menunjukkan 
bahwa ada pengaruh dukungan sosial terhadap resiliensi sebesar 33\% dan $67 \%$ nya merupakan faktor lain yang melatarbelakangi timbulnya resiliensi.

Beberapa aspek Character strength (Chang, 2008) dan dukungan sosial (Friborg, 2002) yang disebutkan merupakan faktor protektif dari resiliensi. Dari penjabaran beberapa tokoh, dapat disimpulkan bahwa Character Strength merupakan sumber daya internal dalam diri individu. sementara menurut Friborg dkk (2006) dukungan sosial merupakan faktor eksternal dari dalam diri yang mempengaruhi resiliensi (ryan \& Catalbiano, 2009).

Berangkat dari penjelasan tersebut, peneliti menentukan untuk meneliti dan melihat perbedaan pengaruh antara faktor internal yang diukur melalui character strength dan faktor eksternal yang diukur melalui dukungan sosial tersebut.

\section{Resiliensi}

Menurut APA Health Center (2004) resiliensi didefinisikan sebagai proses adaptasi yang baik dalam menghadapi kesengsaraan, trauma, peristiwa yang menyedihkan, ancaman, atau bahkan sumber stres yang signifikan seperti keluarga dan atau persoalan mengenai suatu hubungan, masalah-masalah kesehatan yang serius, atau berkaitan dengan tempat kerja dan permasalahan finansial. Singkatnya resiliensi berarti "memantul kembali" dari pengalaman-pengalaman yang menyulitkan (Berman, 2007). Sementara Reivich \& Shatte (2002) mendefinisikan resiliensi sebagai kemampuan untuk beradaptasi untuk tetap teguh dalam situasi yang sulit.

\section{Character Strength}

Character strength dikemukakan oleh Seligman \& Peterson (2004) sebagai sifat positif yang menurut direfleksikan dari pemikiran, perasaan dan tingkah laku dimana seseorang dengan character strength yang baik memiliki kutamaan-keutamaan sepertia kebijaksanaan, keberanian, keadilan, berpengetahuan dan transenden.

Seligman \& Peterson (2004) menjelaskan bahwa karakter-karakter positif manusia dibagi menjadi 24 Character Stregnth yang berada di bawah naungan enam Virtues yakni: Wisdom and Knowledge (Creativity, Curiosity, Open-mindedness, Love of learning, Perspective). Courage (Bravery, Persistence, Integrity, Vitality). Humanity) (Love, Kindness, Social Intelligence). Justice (Citizenship, Fairness, Leadership). Temperance (Forgiveness and mercy, Humility / Modesty, Prudence, Self-regulation). Transcendence (Appreciation of beauty and excellence, Gratitude, Hope, Humor, Spirituality) (Park, Peterson \& Seligman, 2004).

\section{Dukungan Sosial}

Cutrona dan Russel $(1987,1990)$ menjelaskan bahwa dukungan sosial adalah sesuatu yang didapat melalui hubungan interpersonal dimana 
seseorang merasa memiliki keterkaitan emosional, dapat berbagi minat yang dengan orang lain, kemampuannya dihargai, memiliki orang yang dapat diandalkan, dan merasa bertanggungjawab atas kesejahteraan orang lain (Mallinckrodt \& Bennett, 1992).

Aspek - aspek dukungan sosial menurut Cutrona dan Russell (1987) yaitu: Attachment, Social integration, Reassurance of worth, Reliable alliance, Guidance, Opportunity for Nurturance.

\section{METODE PENELITIAN}

Variabel yang ada pada penelitian ini adalah resiliensi sebagai variabel terikat dan character strength dan dukungan sosial sebagai variabel bebas. Penelitian ini menggunakan kuesioner atau angket Skala RQ, Skala VIA-IS dan Skala Social provisions Scale sebagai alat pengumpul data. Subjek yang ada dalam penelitian ini adalah peserta rehabilitasi NAPZA yang terdaftar di PSPP Khusnul Khotimah Tangerang Selatan dengan kriteria berusia 18 tahun ke atas dan memiliki kemampuan baca-tulis dan kemampuan analisis yang masih memadai. Total jumlah subjek yang ada dalam penelitian ini adalah 179 orang. Metode analisis penelitian ini menggunakan PASW 18.0 dan LISREL 8.80.

\section{HASIL DAN BAHASAN}

Hasil uji hipotesis menggunakan teknik analisis regresi berganda adalah sebagai berikut:

Tabel 1

Anova Resiliensi

\begin{tabular}{|c|c|c|c|c|c|c|}
\hline \multicolumn{7}{|c|}{$\begin{array}{c}\text { Anova Resillensi } \\
\text { ANOVA }^{\mathrm{b}}\end{array}$} \\
\hline Model & & Sum of Squares & & Mean Square & $\mathrm{F}$ & \\
\hline & $\frac{\text { Regression }}{\text { Recidual }}$ & $\begin{array}{r}9871.902 \\
5282\end{array}$ & $\begin{array}{r}30 \\
118 \\
\end{array}$ & $\begin{array}{r}329.063 \\
35691\end{array}$ & 9.220 & $.000^{\mathrm{a}}$ \\
\hline & $\frac{\text { Residual }}{\text { Total }}$ & $\begin{array}{r}5 \angle 82.22 L \\
15154.124\end{array}$ & $\frac{148}{178}$ & & & \\
\hline
\end{tabular}

a. Predictors: (Constant), OPP NURTURANCE, VITALITY, REALLIBILITY OF ALLIANCE, ATTACHMENT, GRATITUDE REASSURANCE OF WORTH, SOCIAL INTEGRATION, HUMILITY, PERSPECTIVE, GUIDANCE, HUMOR, LOVE OF LEARNING, APPRETIATION_OF_BEAUTY, FAIRNESS, FORGIVENESS_AND_MERCY, PRESISTANCE, HOPE_, INTEGRITY, SPIRITUALITY, LEADERSHIP, OPEN_MINDEDNESS, BRAVERY, CURIOUSITY, PRUDENCE_, CITIZENSHIP, CREATIVITY, KINDNESS, LOVE, SELF REGULATIŌN

b. Dependent Variable: RESILIENCE

Berdasarkan tabel tersebut, diketahui bahwa $(\mathrm{p}<0.05)$, maka hipotesis nihil yang menyatakan tidak ada pengaruh yang signifikan seluruh IV terhadap kepuasan pernikahan, ditolak. Maka dapat diartikan bahwa ada 
pengaruh yang signifikan dari aspek-aspek character sterngth, aspek-aspek dukungan social terhadap kepuasan resiliensi pada pecandu NAPZA.

\section{Tabel 2}

\section{Koefisien Regresi Independent Variabel}

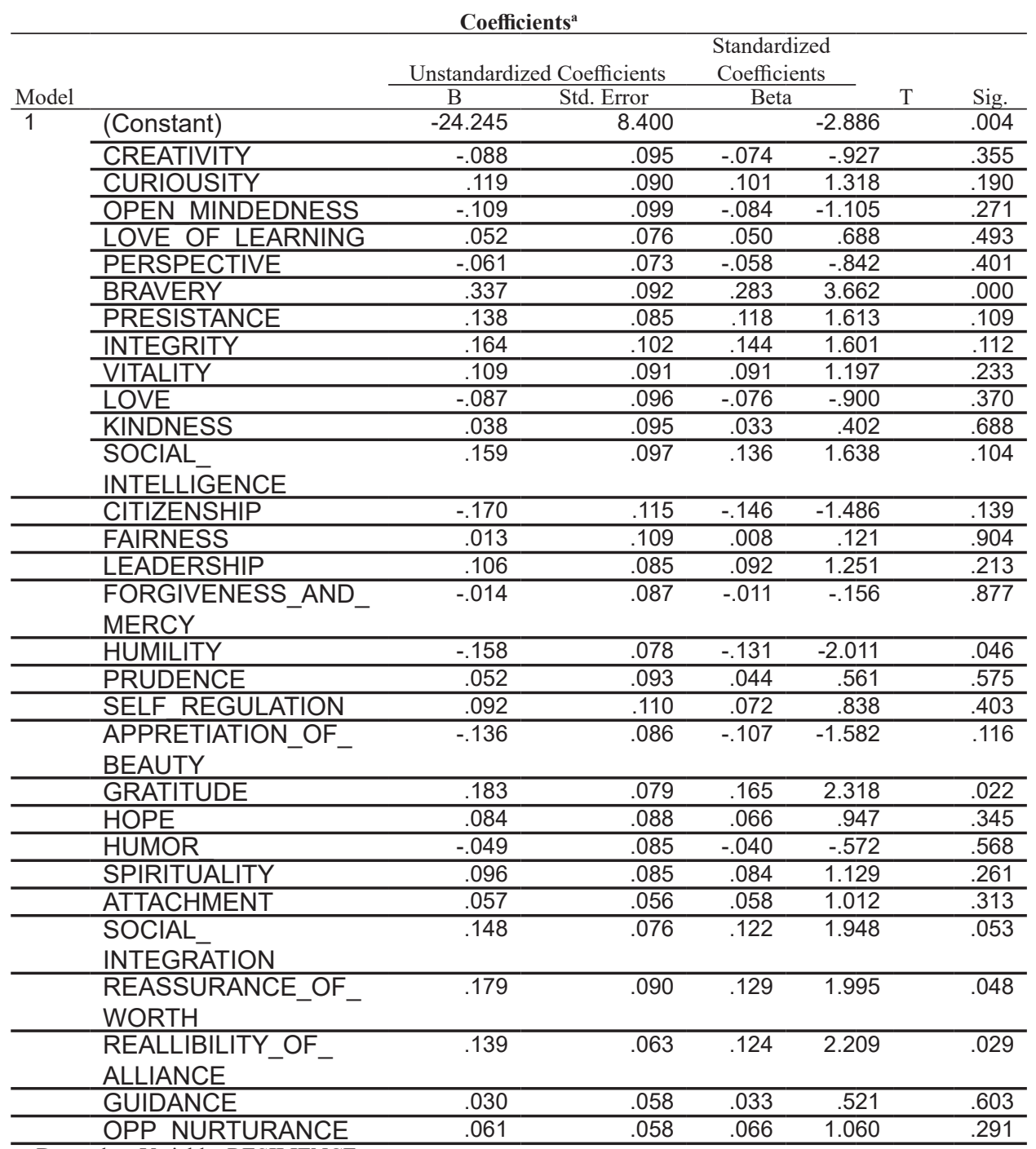

a. Dependent Variable: RESILIENCE

Berdasarkan koefisien regresi pada tabel 2, menunjukkan bahwa persamaan regresi sebagai berikut:

ZResilience $(\mathrm{ZY})=-0.074 \mathrm{Z}($ creativity $)+0.101 \mathrm{Z}($ curiousity $)-0.084$ $\mathrm{Z}($ open mindedness $)+0.50 \mathrm{Z}$ (love of learning $)-0.58 \mathrm{Z}$ (perspective $)+$ 
$0.283 \mathrm{Z}($ bravery $) *+0.118 \mathrm{Z}($ presistance $)+0.144 \mathrm{Z}($ integrity $)+0.091$ $\mathrm{Z}$ (vitality) $-0.076 \mathrm{Z}$ (love $)+0.033 \mathrm{Z}$ (kindness) $+0.136 \mathrm{Z}$ (social intelligence) - 0.146 Z(citizenship) + $0.008 \mathrm{Z}($ fairness $)+0.092 \mathrm{Z}$ (leadership) $0.011 \mathrm{Z}$ (forgiveness and mercy) $-0.131 \mathrm{Z}$ (humility/modesty)* +0.044 $\mathrm{Z}($ prudence $)+0.072 \mathrm{Z}($ self regulation $)-0.107 \mathrm{Z}($ Appreciation of beauty $)+0.165 \mathrm{Z}($ greatitude $) *+0.066 \mathrm{Z}($ hope $)-0.040 \mathrm{Z}($ humor $)+$ $0.084 \mathrm{Z}$ (spirituality) $+0.058 \mathrm{Z}$ (attachment) $+0.122 \mathrm{Z}$ (social integration) $+0.129 \mathrm{Z}$ (reassurance of worth) $*+0.124 \mathrm{Z}$ (reliable alliance) $*+0.033$ $\mathrm{Z}$ (Guidance) + $0.066 \mathrm{Z}$ (opportunity for nurturance) Keterangan: Tanda (*) menunjukkan variabel signifikan

Pada tabel 2, signifikan atau tidaknya koefisien regresi yang dihasilkan dapat dilihat dari nilai sig pada kolom paling kanan. Apabila $\mathrm{P}<0.05$ maka koefisien regresi yang dihasilkan, signifikan pengaruhnya terhadap resiliensi. Berdasarkan data pada tabel di atas, nampak bahwa hanya koefisien bravery, humility/modesty, gratitude, reassurance of woth, reliable alliance, sedangkan yang lainnya tidak ada. Hal ini menunjukkan bahwa dari tiga puluh hipotesis minor hanya terdapat lima yang signifikan. Penjelasan dari nilai koefisien regresi yang diperoleh pada masing-masing IV sebagai berikut:

Variabel Creativity

Pada tabel 4.11 diperoleh nilai koefisien regresi sebesar -0.088 dengan signifikansi $0.355(\mathrm{p}>0.05)$, yang berarti bahwa variabel creativity tidak signifikan.

Variabel Curiousity

Pada tabel 4.11 diperoleh nilai koefisien regresi sebesar 0.119 dengan signifikansi $0.190(\mathrm{p}>0.05)$, yang berarti bahwa variabel curiousity tidak signifikan.

Variabel Open Mindedness

Pada tabel 4.11 diperoleh nilai koefisien regresi sebesar -0.109 dengan signifikansi 0.271 ( $\mathrm{p}>0.05)$, yang berarti bahwa variabel open mindedness tidak signifikan.

Variabel Love of Learning

Pada tabel 4.11 diperoleh nilai koefisien regresi sebesar 0.052 dengan signifikansi 0.493 ( $\mathrm{p}>0.05)$, yang berarti bahwa variabel love of learning tidak signifikan.

Variabel Perspective

Pada tabel 4.11 diperoleh nilai koefisien regresi sebesar -0.061 dengan signifikansi $0.401(\mathrm{p}>0.05)$, yang berarti bahwa variabel perspective tidak signifikan. 


\section{Variabel Bravery}

Pada tabel 4.11 diperoleh nilai koefisien regresi sebesar 0.337 dengan signifikansi $0.000(\mathrm{p}<0.05)$, yang berarti bahwa variabel bravery secara positif mempengaruhi resiliensi serta signifikan. Jadi, semakin tinggi bravery maka semakin tinggi resiliensi pengguna NAPZA.

Variabel Presistance

Pada tabel 4.11 diperoleh nilai koefisien regresi sebesar 0.138 dengan signifikansi $0.109(\mathrm{p}>0.05)$, yang berarti bahwa variabel presistance tidak signifikan.

Variabel Integrity

Pada tabel 4.11 diperoleh nilai koefisien regresi sebesar 0.164 dengan signifikansi $0.112(\mathrm{p}>0.05)$, yang berarti bahwa variabel integrity tidak signifikan.

Variabel Vitality

Pada tabel 4.11 diperoleh nilai koefisien regresi sebesar 0.109 dengan signifikansi $0.223(\mathrm{p}>0.05)$, yang berarti bahwa variabel tidak signifikan.

Variabel Love

Pada tabel 4.11 diperoleh nilai koefisien regresi sebesar -0.087 dengan signifikansi $0.370(\mathrm{p}>0.05)$, yang berarti bahwa variabel love tidak signifikan.

Variabel Kindness

Pada tabel 4.11 diperoleh nilai koefisien regresi sebesar 0.038 dengan signifikansi $0.668(\mathrm{p}>0.05)$, yang berarti bahwa variabel kindness tidak signifikan.

Variabel Social Intelligence

Pada tabel 4.11 diperoleh nilai koefisien regresi sebesar 0.159 dengan signifikansi $0.104(\mathrm{p}>0.05)$, yang berarti bahwa variabel social intelligence tidak signifikan.

Variabel Citizenship

Pada tabel 4.11 diperoleh nilai koefisien regresi sebesar -0.170 dengan signifikansi $0.139(\mathrm{p}>0.05)$, yang berarti bahwa variabel citizenship tidak signifikan.

Variabel Fairness

Pada tabel 4.11 diperoleh nilai koefisien regresi sebesar 0.013 dengan signifikansi $0.904(p>0.05)$, yang berarti bahwa variabel fairness tidak signifikan.

Variabel Leadership

Pada tabel 4.11 diperoleh nilai koefisien regresi sebesar 0.106 dengan signifikansi $0.213(\mathrm{p}>0.05)$, yang berarti bahwa variabel leadership 
tidak signifikan.

Variabel Forgiveness and Mercy

Pada tabel 4.11 diperoleh nilai koefisien regresi sebesar -10.014 dengan signifikansi $0.877(\mathrm{p}>0.05)$, yang berarti bahwa variabel forgiveness and mercy tidak signifikan.

Variabel Humility / modesty

Pada tabel 4.11 diperoleh nilai koefisien regresi sebesar - 0.158 dengan signifikansi $0.046(\mathrm{p}>0.05)$, yang berarti bahwa variabel humility secara negatif mempengaruhi resiliensi serta signifikan. Jadi, semakin tinggi humility / modesty maka semakin rendah resiliensi pengguna NAPZA

\section{Variabel Prudence}

Pada tabel 4.11 diperoleh nilai koefisien regresi sebesar 0.052 dengan signifikansi $0.575(\mathrm{p}>0.05)$, yang berarti bahwa variabel tidak signifikan.

Variabel Self Regulation

Pada tabel 4.11 diperoleh nilai koefisien regresi sebesar 0.092 dengan signifikansi 0.403 ( $p>0.05)$, yang berarti bahwa variabel self regulaation tidak signifikan.

Variabel Appreciation of Beauty

Pada tabel 4.11 diperoleh nilai koefisien regresi sebesar - 0.136 dengan signifikansi $0.0116(\mathrm{p}>0.05)$, yang berarti bahwa variabel appreciation of beauty tidak signifikan.

Variabel Gratitude

Pada tabel 4.11 diperoleh nilai koefisien regresi sebesar 0.183 dengan signifikansi $0.022(\mathrm{p}<0.05)$, yang berarti bahwa variabel gratitude secara positif mempengaruhi resiliensi serta signifikan. Jadi, semakin tinggi gratitude maka semakin tinggi resiliensi pengguna NAPZA.

Variabel Hope

Pada tabel 4.11 diperoleh nilai koefisien regresi sebesar 0.084 dengan signifikansi $0.345(\mathrm{p}>0.05)$, yang berarti bahwa variabel hope tidak signifikan.

Variabel Humor

Pada tabel 4.11 diperoleh nilai koefisien regresi sebesar -0.049 dengan signifikansi $0.568(\mathrm{p}>0.05)$, yang berarti bahwa variabel tidak signifikan.

Variabel Spirituality

Pada tabel 4.11 diperoleh nilai koefisien regresi sebesar 0.096 dengan signifikansi 0.261 ( $\mathrm{p}>0.05)$, yang berarti bahwa variabel spirituality tidak signifikan 
Variabel Attachment

Pada tabel 4.11 diperoleh nilai koefisien regresi sebesar 0.057 dengan signifikansi $0.313(\mathrm{p}>0.05)$, yang berarti bahwa variabel attacment tidak signifikan.

Variabel Social Integration

Pada tabel 4.11 diperoleh nilai koefisien regresi sebesar 0.148 dengan signifikansi 0.053 ( $\mathrm{p}>0.05$ ), yang berarti bahwa variabel social integration tidak signifikan.

Variabel Reassurance of Worth

Pada tabel 4.11 diperoleh nilai koefisien regresi sebesar 0.179 dengan signifikansi $0.048(\mathrm{p}<0.05)$, yang berarti bahwa variabel reassurance of worth secara positif mempengaruhi resiliensi serta signifikan. Jadi, semakin tinggi reassurance of worth maka semakin tinggi resiliensi pengguna NAPZA.

Variabel Reallibility of Alliance

Pada tabel 4.11 diperoleh nilai koefisien regresi sebesar 0.139 dengan signifikansi $0.029(\mathrm{p}<0.05)$, yang berarti bahwa variabel reallibility of alliance secara posotif mempengaruhi resiliensi serta signifikan. Jadi, semakin tinggi reallibility of alliance maka semakin tinggi resiliensi pengguna NAPZA.

Variabel Guidance

Pada tabel 4.11 diperoleh nilai koefisien regresi sebesar 0.030 dengan signifikansi $0.603(\mathrm{p}>0.05)$, yang berarti bahwa variabel guidance tidak signifikan.

Variabel Oppurtunity for Nurturance

Pada tabel 4.11 diperoleh nilai koefisien regresi sebesar 0.061 dengan signifikansi $0.291(\mathrm{p}>0.05)$, yang berarti bahwa variabel oppurtunity for nurturance tidak signifikan.

\section{Besaran Muatan IV terhadap DV}

Pada bahasan sebelumnya, dapat diketahui bahwa terdapat lima IV yang memiliki pengaruh signifikan terhadap resliensi, yaitu bravery, humility I modesty, gratitude, yang merupakan dimensi dari variabel character strength, dan reassurance of worth dan reliable alliance yang merupakan dimensi dari variabel dukungan sosial.

Peneliti juga ingin mengetahui bagaimana besaran muatan atau kontribusi dari masing-masing independent variable berpengaruh terhadap resiliensi, lalu mengurutkannya dari besaran muatan yang paling besar 
hingga yang terkecil. Pada akhirnya akan diketahui prediktor mana yang memiliki pengaruh paling besar terhadap resiliensi.

Berdasarkan data pada tabel 2 dapat diketahui bahwa urutan prediktor yang memiliki kontribusi terhadap resiliensi dari yang terbesar hingga yang terkecil adalah bravery dengan kontribusi sebesar 0.283, gratitude dengan kontribusi sebesar 0.165, humility / modesty dengan kontribusi sebesar 0.131 , reassurance of worth dengan kontribusi sebesar 0.129 , dan reliable alliance dengan kontribusi sebesar 0.124.

\section{KESIMPULAN DAN SARAN}

Berdasarkan hasil analisis data serta pengujian hipotesis menggunakan perhitungan Anova yang telah dikemukakan pada bab sebelumnya, maka kesimpulan yang dapat diambil dari penelitian ini adalah

Terdapat pengaruh yang signifikan Pada variabel character strength terhadap resiliensi pada pengguna NAPZA, yaitu bravery $(0.283)$, humility/modesty (-0.131), gratitude (0.165).

Terdapat pengaruh yang signifikan pada variabel dukungan sosial terhadap resiliensi pada pengguna NAPZA, yaitu reassurance of worth (0.129), dan reliable alliance (0.124).

Apabila dilihat dari besaran muatan pengaruh IV terhadap DV dari kelima IV tersebut yakni bravery, humility / modesty, gratitude, reassurance of worth, dan reliability of alliance yang memiliki kontribusi paling besar terhadap resiliensi adalah bravery, dimana bravery memberikan pengaruh beta $\left({ }^{\beta}\right)$ sebesar 0.283 dengan signifikansi sebesar 0.000 , humility / modesty memberikan pengaruh beta $\left({ }^{\beta}\right)$ sebesar -0.131 dengan signifikansi sebesar 0.046 , gratitude memberikan pengaruh beta ${ }^{\beta}$ ) sebesar 0.165 dengan signifikansi sebesar 0.022 , reassurance of worth memberikan pengaruh beta $\left({ }^{\beta}\right)$ sebesar 0.129 dengan signifikansi sebesar 0.048 , reallibility of alliance memberikan pengaruh beta $\left({ }^{\beta}\right)$ sebesar 0.124 dengan signifikansi sebesar 0.029 .

Apabila dilihat dari jenis faktor protektif dari resiliensi secara internal dan eksternal, maka dapat disimpulkan bahwa pada penelitian ini, faktor protektif internal memiliki kontribusi lebih besar terhadap resiliensi pada pengguna NAPZA dibanding dengan faktor protektif eksternal. 
Berdasarkan penulisan penelitian ini, peneliti menyadari bahwa masih terdapat banyak kekurangan di dalamnya. Untuk itu, peneliti memberikan beberapa saran untuk bahan pertimbangan sebagai penyempurnaan penelitian selanjutnya.

Bagi peneliti selanjutnya yang ingin melakukan penelitian pada pengguna

NAPZA dan sejenisnya, agar menggunakan istilah dan bahasa yang sederhana pada tiap-tiap item di kuesioner penelitian mengingat kondisi dan kapasitas dari responden yang memang memiliki keterbatasan dalam menganalisa dikarenakan efek dari pengguanan NAPZA.

Bagi peneliti selanjutnya yang ingin meneliti dengan tema serupa yang menggunakan teori yang dikemukakan Peterson \& Seligman dimana memiliki skala yang memiliki cukup banyak item, agar mengurangi jumlah item pada kuesioner yang diberikan atau dapat mencari teori lain yang memiliki item skala baku yang lebih sedikit.

Bagi peneliti selanjutnya yang ingin meneliti dengan independent variable dan dependent variable yang sama, dengan responden berbeda atau sama, agar mencari jumlah responden yang lebih banyak dari penelitian ini guna meningkatkan validitas penelitian.

Dari ketigapuluh independen variabel yang ada, keseluruhan IV menyumbang pengaruh $65.1 \%$ secara bersama-sama. Sisanya sebanyak $34.9 \%$ dipengaruhi variabel lainnya. Oleh sebab itu, disarankan untuk penelitian selanjutnya agar meneliti atau menganalisa lebih lanjut variabel lainnya yang mungkin memengaruhi variabel resiliensi secara signifikan seperti jangka waktu rehabilitasi, jenis treatmen yang didapat, frekuensi relaps, tipe kepribadian, empati, konsep diri, optimisme dll.

\section{Referensi}

Cloninger, C. Robert. (2006). The science of well-being: an integrated approach to mental health and its disorders. World Psychiatry: USA

Cutrona, C.E., \& Rusell,D. W. (1987). The Provisions of Social Relationships and adaptation to Stress. Rev. JAI press, Inc.

Hasyim, rizkia noor faiza. (2009). Pengaruh Dukungan Sosial Terhadap Resiliensi Napi Remaja Di Lembaga Pemasyarakatan Anak (Lapas Kelas Iia Anak) Blitar. Skripsi UIN: Malang 
Mallinckrodt, B., Bennet, J. (1992). Social Support and the Impact of Jobloss in Dislocated Blue-Collar Workers. Journal of Counseling Psychology. 39(4). 482

Mutimer. Annete., Reece \& Matthews. (2007). Child Resilience: Relationships between Stress, Adaptation and Family Functioning. 3 (1): $16-25$

Ibrahim, Fauziah., Kumar, Naresh. (2009). Factors Effecting Drug Relapse in Malaysia: An Empirical Evidence. Ccsenet.org

Park, Nasoon., Peterson \& Seligman. (2004). STRENGTHS OF CHARACTER AND WELL-BEING: Journal of Social and Clinical Psychology

Reivich, K., Shatte, A. (2002). The Resilience Factor: 7 Essential Skills for Overcoming Life's Inevitable Obstacles. New york: Broadway Books Ryan, Linda., Caltabiano, Marie L. (2009). Development of a New Resilience Scale: The Resilience in Midlife Scale (RIM Scale). Ccsenet.org

Seligman, M. E. P., Peterson, C. (2004). Character Strengths and Virtues: a Handbook and Classification, Oxford University Press and the American Psychological Association: USA

Suriakusumah, Kusman. (2012). Komunika edisi ke-8: Mereka itu Sakit bukan Kriminal. Komunika Tabloid: Jakarta

Witkiewitz, Katie., Marlatt, G. Alan (2004). Relapse Prevention for Alcohol and Drugs Problems: That was Zen Thins is Tao. American Psychologist: USA 